\title{
ADAMTS13 gene; a novel splicing site mutation in a case with thrombotic thrombocytopenic purpura
}

\author{
Sepideh Zununi Vahed ${ }^{1}$, Alessandra Cremaschi ${ }^{2}$, Behzad Zaker ${ }^{1}$, Seyed Sadroddin Rasi Hashemi ${ }^{1}$, \\ Mohammadreza Ardalan ${ }^{*}$ (D)
}

${ }^{1}$ Kidney Research Center, Tabriz University of Medical Sciences, Tabriz, Iran

${ }^{2}$ Istituto di Ricerche Farmacologiche Mario Negri IRCCS, Bergamo, Italy

\section{A R T I C LE IN F O}

Article Type:

Case Report

\section{Article History:}

Received: 4 August 2020

Accepted: 12 October 2020

Published online: 30 October 2020

\section{Keywords:}

TTP, ADAMTS13,

Gene polymorphism,

Von Willebrand factor,

Plasmapheresis

\begin{abstract}
A B S T RA C T
A plasma protease, ADAMTS13, cleaves the von Willebrand factor (VWF) and its deficiency is associated with the pathogenesis of thrombotic thrombocytopenic purpura (TTP). According to the Human Gene Mutation Database (HGMD), about 150 mutations have been identified in the ADAMTS13 gene. A 23-year-old man, with hematuria and gingival bleeding was admitted to our University Hospital. Four years ago he was diagnosed with a TTP history. During these years, he was under intermittent plasma exchange. A blood sample was taken for genetic study. He effectively responded to one session of fresh frozen plasma replacement and plasma exchange. Genetic study indicated that this case carries two heterozygous mutations in ADAMTS13 gene; a novel splicing variant (c.2610+5G>A) and a nonsense p.Arg910X mutation that previously is reported to relate to TTP. The novel variant predicted to result in an aberrant ADAMTS13 transcript processing.
\end{abstract}

Implication for health policy/practice/research/medical education:

The c.2728C >T (p.Arg910X) mutation in ADAMTS13 gene was found in a patient with congenital TTP. Moreover, we found c. $2610+5 \mathrm{G}>\mathrm{A}$ mutation, a novel splicing variant, that affects exon 20 and encodes for the ADAMTS13's thrombospondin type-1 fifth domain in this case. This novel variant expected to cause aberrant ADAMTS13 transcript processing.

Please cite this paper as: Zununi Vahed S, Cremaschi A, Zaker B, Rasi Hashemi SS, Ardalan M. ADAMTS13 gene; a novel splicing site mutation in a case with thrombotic thrombocytopenic purpura. J Nephropharmacol. 2021;10(2):e17. DOI: 10.34172/ npj.2021.17.

\section{Introduction}

Thrombotic thrombocytopenic purpura(TTP) isidentified by small-vessel platelet-rich thrombi and presents with microangiopathic hemolytic anemia, thrombocytopenia, and consequent multiorgan dysfunction (1). Deficiency of a plasma protease ADAMTS13 cleaving the von Willebrand factor (VWF), can result in VWF perseverance that plays an important role in the pathogenesis of TTP (2). ADAMTS13 deficiency is determined by either genetic causes (congenital TTP) or by autoantibodies against the protease (acquired TTP). Congenital TTP, responsible for less than $5 \%$ of cases $(3,4)$, is an autosomal recessive disorder (2) due to compound heterozygous or homozygous mutations in the ADAMTS13 gene, which is located on chromosome 9.

According to the Human Gene Mutation Database (HGMD), about 150 mutations of the ADAMTS13 gene have been recognized so far. They included: 113 missense/ nonsense mutations, 10 splicing mutations (Table 1), 21 small deletions, 7 small insertions, and 5 gross deletions.

In this report, we describe a case of a young male from Iran suffers from congenital TTP and carries two heterozygous mutations in ADAMTS13 gene: a novel splicing variant (c.2610+5G $>A$ ) and a nonsense p.Arg910X mutation that previously is reported to associate with TTP. The novel variant predicted to result in an aberrant ADAMTS13 transcript processing.

\section{Case Report}

A 23-year-old man, with hematuria and gingival bleeding was admitted to our University Hospital. Four years he was diagnosed with a clinical history of TTP. After TTP was diagnosed, he received intermittent sessions of plasmapheresis (once a week) for one year. Urinalysis 
revealed hematuria and peripheral blood examination disclosed schistocytes. The laboratory findings at the time of admission presented in Table 2. ADAMTS13 enzyme activity was less than $10 \%$ during active disease. We did not measure the autoantibody titer of ADAMTS13. The patient received 2 liter per day plasmapheresis with fresh frozen plasma (FFP) replacement and after clinical improvement (platelet count $>100000 / \mathrm{mm}^{3}$, lactate dehydrogenase (LDH) $<600$ (units/L)), he was discharged. Thereafter, he was under our frequent follow up and still now he is receiving once weekly plasma exchange (2 liters per session).

DNA was extracted from the patient's peripheral blood cells and genetic analysis was performed at Mario Negri Institute for Pharmacological Research in Bergamo (Italy). DNA from healthy parents and siblings was not available for genotyping.

All coding exons and flanking intronic regions of the ADAMTS13 gene were analyzed by Sanger sequencing. We recognized a heterozygous mutation, located at exon 21 , leading to the insertion of a premature stop codon

Table 1. Reported mutations in splicing sites of ADAMTS13 gene TTP patients

\begin{tabular}{lll}
\hline $\begin{array}{l}\text { Accession } \\
\text { Number }\end{array}$ & HGMD splicing mutation & References \\
\hline CS126162 & IVS1 as -1 G-C (c.106-1G>C) & van Dorland et al (8) \\
CS043116 & IVS3 ds +1 G-A (c.330+1G>A) & Uchida et al (9) \\
CS040521 & IVS4 ds +1 G-A (c.414+1G>A) & Matsumoto et al (10) \\
CS040522 & IVS6 ds +1 G-A (c.686+1G>A) & Matsumoto et al (10) \\
CS058243 & IVS6 as -2 A-G (c.687-2A>G) & van Dorland et al (8) \\
CS040523 & IVS10 ds +2 T-G (c.1244+2T>G) & Matsumoto et al (10) \\
CS126173 & IVS11 ds -1 G-C & van Dorland et al (8) \\
CS044745 & IVS11 as -1 G-A & Veyradier et al (11) \\
CS013075 & IVS13 ds +5 G-A (c.1584+5G>A) & Levy et al (12) \\
CS123086 & IVS15 ds +1 G-A (c.1786+1G>A) & Prestidge et al (13) \\
\hline
\end{tabular}

(c.2728C>T, NM_139025.4, p.Arg910X). This mutation is absent in public databases (dbSNP151, 1000 Genomes Project, Exome Aggregation Consortium, The Genome Aggregation Database), but it has been previously reported in a case of TTP with childhood onset (2). We identified a second heterozygous mutation (c.2610+5G $>$ A) laying in intron 20, predicted to probably affect the splicing of exon 20. This variant has been reported neither in public databases nor in TTP patients. In silico analyses predicted that the possibility of the exon 20 correct splicing declines from 0.983 to 0 versus the wild-type sequence (GenScan software) (5) in the mutant sequence. Furthermore, an aberrant exon 20 characterized by the retention of 21 -base pairs was predicted with a probability of 0.572 , leading to an in-frame insertion of 7 amino acids (VNALGMR) in the protein sequence.

Additional predictions with the Human Splicing Finder software (6) confirmed that this mutation causes the break of the wild-type donor splicing site.

\section{Discussion}

Here, we describe the clinical course of a patient with congenital TTP in whom we identified the underlying genetic abnormality. The c.2728C $>\mathrm{T}$ (p.Arg910X) mutation found in our patient was previously reported and its functional effect was shown. However, the c. $2610+5 \mathrm{G}>\mathrm{A}$ mutation, which affects exon 20 and encodes for the ADAMTS13's thrombospondin type1 fifth domain, is novel. As shown, it is predicted to interfere with normal ADAMTS13 mRNA splicing but future studies are needed to confirm the functional effect of this substitution. An accurate splicing of premRNA is a serious stage in protein translation and posttranscriptional regulation. Consensus "cis-acting" splicing sequences existence in exon-intron boundaries is essential for recognition by splicing machinery. By creating new splicing sites, splicing regulatory sequences, disruption of existing splice sites, or activating the cryptic splicing sites,

Table 2. The laboratory findings of the case at the time of admission

\begin{tabular}{|c|c|c|c|}
\hline Hematological tests & (Normal range) & Serological tests & (Normal range) \\
\hline $\mathrm{PLC} / \mathrm{mm}^{3}$ & 22000 & Creatinine (mg/dL) & 1.1 \\
\hline $\mathrm{WBC} / \mathrm{mm}^{3}$ & 8800 & URA (mg/dL) & $44(19-44)$ \\
\hline M.C.V (fl) & 79 (77-97) & Sodium (meq/L) & 144 \\
\hline M.C.H (pgm) & $26(26-32)$ & Potassium (meq/L) & 4.4 \\
\hline M.C.H.C (\%) & $34(32-36)$ & ALP (IU/L) & 107 \\
\hline SGOT (IU/L) & $29(0-31)$ & Calcium (mmol/L) & $1.07(1.13-1.30)$ \\
\hline SGPT (IU/L) & $19(0-41)$ & Phosphors ( mg/dL) & $2.7(2.6-4.5)$ \\
\hline Bilirubin, Total (mg/dL) & $3.7(0.1-1.2)$ & LDH level (U/L) & 2772 \\
\hline Bilirubin, Direct (mg/dL) & $0.8(0-0.4)$ & PTT (seconds) & 33 \\
\hline Bilirubin, Indirect (mg/dL) & $2.9(0.1-0.8)$ & PT (seconds) & 13 \\
\hline Hemoglobin & $12.3 \mathrm{mg} / \mathrm{mL}$ & & \\
\hline
\end{tabular}

PLC: platelet count, WBC: white blood cell count, LDH: lactate dehydrogenase, ALP: Alkalin phosphatase, PTT: partial thromboplastin time, MCV: mean corpuscular volume, PT: prothrombin time. 
mutations on these sequences can result in an aberrant transcript of the mutated gene or inappropriate removal of intron, and modifications of the open reading frame. The impact of the specific mutation needs to be confirmed with functional studies (7).

Congenital TTP is an autosomal recessive disorder. Thus, mutations have to affect both alleles of ADAMTS13. Unfortunately, DNA from patient's parents was not available to assess the segregation of the $c .2728 \mathrm{C}>\mathrm{T}$ and the c. $2610+5 \mathrm{G}>\mathrm{A}$. However, his ADAMTS13 activity was less than $10 \%$, leading us to reasonably assume that the two mutations are carried on different chromosomes, and to speculate that the c. $2610+5 \mathrm{G}>\mathrm{A}$ disrupts the correct splicing of ADAMTS13 transcript.

\section{Acknowledgements}

We greatly acknowledge Professor Giuseppe Remuzzi, Dr Marina Noris, and Dr Elena Bresin for their help and support. Genetic study was done at the Laboratory of Immunology and Genetics of Rare Diseases at the Clinical Research Center for Rare Diseases "Aldo e Cele Daccò" at the Istituto di Ricerche Farmacologiche Mario Negri IRCCS, Bergamo-Italy.

\section{Authors' contribution}

MRA was the principal investigator of the study who prepared the concept and design. BZ and SZV prepared the draft of the manuscript. AC and JE revised the manuscript and critically evaluated the intellectual contents. All authors have read and approved the content of the manuscript and confirmed the accuracy or integrity of any part of the work.

\section{Conflicts of interest}

The authors declare that they have no competing interests.

\section{Ethical considerations}

Ethical issues (including plagiarism, data fabrication, double publication) have been completely observed by the authors. The patient gave the consent to publish as a case report.

\section{Funding/Support}

This work was financially supported by the Kidney Research Center at Tabriz University of Medical Sciences, Tabriz, Iran (Grant \# 62839).

\section{References}

1. Zheng X, Chung D, Takayama TK, Majerus EM, Sadler JE, Fujikawa K. Structure of von Willebrand factor-cleaving protease (ADAMTS13), a metalloprotease involved in thrombotic thrombocytopenic purpura. J Biol Chem.
2001;276:41059-63. doi 10.1074/jbc.C100515200

2. Schneppenheim R, Budde U, Oyen F, Angerhaus D, Aumann V, Drewke E, et al. von Willebrand factor cleaving protease and ADAMTS13 mutations in childhood TTP. Blood. 2003;101:1845-50. doi:10.1182/blood-2002-08-2399

3. Romao de Souza V, Jr., Beatriz Cavalcante de Oliveira A, Maria Vanderlei A, Queiroz da Mota Silveira Aroucha A, Pontes Duarte B, Nunes Machado A, et al. Inherited thrombotic thrombocytopenic purpura mimicking immune thrombocytopenic purpura during pregnancy: a case report. J Med Case Rep. 2018;12:15. doi:10.1186/ s13256-017-1545-3

4. Moatti-Cohen M, Garrec C, Wolf M, Boisseau P, Galicier L, Azoulay E, et al. Unexpected frequency of UpshawSchulman syndrome in pregnancy-onset thrombotic thrombocytopenic purpura. Blood. 2012;119(24): 5888-97. doi:10.1182/blood-2012-02-408914

5. Burge C, Karlin S. Prediction of complete gene structures in human genomic DNA. J Mol Biol. 1997;268:78-94. doi:10.1006/jmbi.1997.0951

6. Desmet FO, Hamroun D, Lalande M, Collod-Béroud G, Claustres M, Béroud C. Human Splicing Finder: an online bioinformatics tool to predict splicing signals. Nucleic Acids Res. 2009;37:e67. doi:10.1093/nar/gkp215

7. Anna A, Monika G. Splicing mutations in human genetic disorders: examples, detection, and confirmation. J Appl Genet. 2018;59(3):253-268. doi: 10.1007/s13353-018-04447

8. van Dorland HA, Taleghani MM, Sakai K, Friedman KD, George JN, Hrachovinova I. The International Hereditary Thrombotic Thrombocytopenic Purpura Registry: key findings at enrollment until 2017, Haematologica. 2019;104:2107-15. doi: 10.3324/haematol.2019.216796.

9. Uchida $T$, Wada $H$, Mizutani $M$, Iwashita $M$, Ishihara $\mathrm{H}$, Shibano $\mathrm{T}$, et al. Identification of novel mutations in ADAMTS13 in an adult patient with congenital thrombotic thrombocytopenic purpura. Blood. 2004;104:2081-3. doi: 10.1182/blood-2004-02-0715

10. Matsumoto M, Kokame K, Soejima K, Miura M, Hayashi S, Fujii Y, et al. Molecular characterization of ADAMTS13 gene mutations in Japanese patients with UpshawSchulman syndrome. Blood. 2004;103:1305-10. doi: 10.1182/blood-2003-06-1796

11. Veyradier A, Lavergne JM, Ribba AS, Obert B, Loirat C, Meyer D, et al. Ten candidate ADAMTS13 mutations in six French families with congenital thrombotic thrombocytopenic purpura (Upshaw-Schulman syndrome). J Thromb Haemost. 2004;2:424-9.

12. Levy GG, Nichols WC, Lian EC, Foroud T, McClintick JN, McGee BM, et al. Mutations in a member of the ADAMTS gene family cause thrombotic thrombocytopenic purpura. Nature. 2001;413:488-94. doi:10.1038/35097008

13. Prestidge TD, Rurali E, Wadsworth L, Wu JK, Moore JC, Bresin E. Congenital thrombotic thrombocytopenic purpura (cTTP) with two novel mutations. Pediatr Blood Cancer. 2012;59:1296-8. doi:10.1002/pbc.24159

Copyright $\odot 2021$ The Author(s); Published by Published by Society of Diabetic Nephropathy Prevention. This is an open-access article distributed under the terms of the Creative Commons Attribution License (http://creativecommons.org/licenses/by/4.0), which permits unrestricted use, distribution, and reproduction in any medium, provided the original work is properly cited. 